of the new antibodies have $k_{\text {on }}$ values that are ten times higher than for the secondary antibodies related to the first set of clones; that is, at a given concentration of antigen, the newly arising set of antibodies will react ten times faster than the others. Foote and Milstein argue that the antibodies are selected because of their faster reaction rates.

Lawrence and Springer ${ }^{2}$ deal with the interaction of neutrophils with endothelium. During inflammation reactions in vivo, a cell is stopped in its flow through a capillary and rolls along the endothelial surface. The cell then adheres strongly to the endothelial surface before passing between cells into the tissue. Much work has been going on to identify the molecules that are involved in these interactions (for review and terminology see refs 4 and 5), and the importance of the integrins LFA-1 and Mac-1 binding to ICAM-1, a member of the immunoglobulin superfamily of adhesion receptors, was initially established. When ICAM-1 is inserted into a lipid bilayer on glass plates, activated neutrophils adhere well in static conditions and stay strongly attached if solution flow is initiated across the cells. But when the cells are applied under conditions of solution flow, neither resting nor activated neutrophils attach to ICAM-1 and it is clear that the integrins are not involved in the rolling reaction in vivo. Instead the initial reaction seems to be mediated by molecules of the selectin superfamily, and Lawrence and Springer establish a role for CD62 (also known as PADGEM or GMP-140). When CD62 is incorporated into lipid on the glass slide, a rolling reaction with unactivated neutrophils is initiated. Once this is established, it is believed that integrin binding comes into play to trigger the later events provided the neutrophils also undergo activation with chemotactic agents.

Why is CD62 effective in catching neutrophils as they flow past whereas ICAM-1 is not? The ligand for CD62 is not precisely established but is thought to involve sialylated carbohydrate epitopes related to the Lewis $\mathrm{x}$ determinant (for review see ref. 5). Lawrence and Springer suggest that CD62 works because the rate of reaction with its carbohydrate epitope is faster than for interactions that involve protein epitopes. The $k_{\text {on }}$ values for lectin - carbohydrate reactions have been measured at $5 \times 10^{4}$ and $5 \times 10^{5} \mathrm{M}^{-1} \mathrm{~s}^{-1}$ for concanavalin $\mathrm{A}$ and Ricinus communis lectin, respectively ${ }^{6}$ and these are not higher than the constants for reactions between antibodies and proteins. However, Lawrence and Springer say that carbohydrate ligands may be found at the end of flexible chains leading to a more rapid rate in the complex situation of opposed cell surfaces. Another possibility is that the concentration of the carbohydrate epitopes is high at the cell surface and leads to the required rapid reaction.

On neutrophils the Lewis $\mathrm{x}$ carbohydrate can be expressed on glycolipids or on glycoproteins with $\mathrm{O}$-linked or $\mathrm{N}$ linked carbohydrate structures ${ }^{5,7}$, and some of the molecules that may be involved are shown in the figure. An interesting molecule of possible relevance is leukosialin (CD43) which is expressed at high levels on neutrophils ${ }^{7,8}$. This molecule extends to a length of $45 \mathrm{~nm}$ and carries about 70 $O$-linked carbohydrate structures on the 224 amino acids of its extracellular domain. It may be that CD62 reacts with leukosialin or a similar structure at the periphery of the neutrophil surface and that the close clustering of carbohydrate epitopes yields a high local concentration leading to rapid on-rates in the reaction.

The concept of affinity has been invoked to explain all sorts of complex events; yet, as we better understand the real reactions, equilibrium considerations become largely irrelevant. Instead it is essential to understand the process of events in dynamic cell - cell interactions. Can molecules interact sufficiently quickly to be relevant? How many molecules must be engaged for a biologically relevant effect? How long must engagement occur for signals to be given? How important is the local organization of ligands at the cell surface? Which molecules act synergistically? It is questions such as these that will have to be answered if the complexity of cell interactions is to be resolved.

Alan F. Williams is in the MRC Cellular Immunology Research Unit, Sir William Dunn School of Pathology, University of Oxford, Oxford OX1 3RE, UK.

1. Foote, J. \& Milstein, C. Nature 352, 530-532 (1991)

2. Lawrence, M. B. \& Springer, T. A. Cell 65, $859-873$ (1991).

3. Mason, D. W. \& Williams, A. F. in Handbook of Experimental Immunology, Vol. 1, 4th edn (eds Weir D. M. et al.) 38.1-38.17 (Blackwell Scientific, Oxford, 1986).

4. Springer, T. A. Nature 346, 425-433 (1990)

5. Springer, T. A. \& Lasky, L. A. Nature $349,196-197$ (1991).

6. Podder, S. K., Surolia, A. \& Bachhawat, B. K. FEBS Letts 85, 313-316 (1978)

7. Fukuda, M., Carlsson, S. R., Klock, J. C. \& Dell, A. J. biol. Chem. 261, 12796-12806 (1986).

8. Cyster, J. G., Shotton, D. M. \& Williams, A. F. EMBO J. 4, 893-902 (1991).

9. Nermut, M. V. et al. EMBO J. 7, 4093-4099 (1988)

10. Diamond, M. S. et al. Cell 65, 961-971 (1991)

11. Johnston, G. I. Cook, R. G. \& McEver, R. P. Cell 56, 1033-1044 (1989).

12. Rosen, H. \& Law, S. K. A. Curr. Top. Microbiol. Immunol. 153, 99-122 (1989)

\title{
Reflections on a zoologist
}

DESMOND Morris is best known for his popularizations of behavioural studies, including The Naked Ape and Manwatching and even for an in-depth study of the psychology of football crowds, The Soccer Tribe. But with a catalogue of over 850 canvasses to his name, Morris is also a formidable artist. He admits a debt to the French surrealist Yves Tanguy, a mariner whose static images, influenced perhaps by desolate beachscapes, Morris contrasts with his own dynamic creations, dominated by "sexuality,

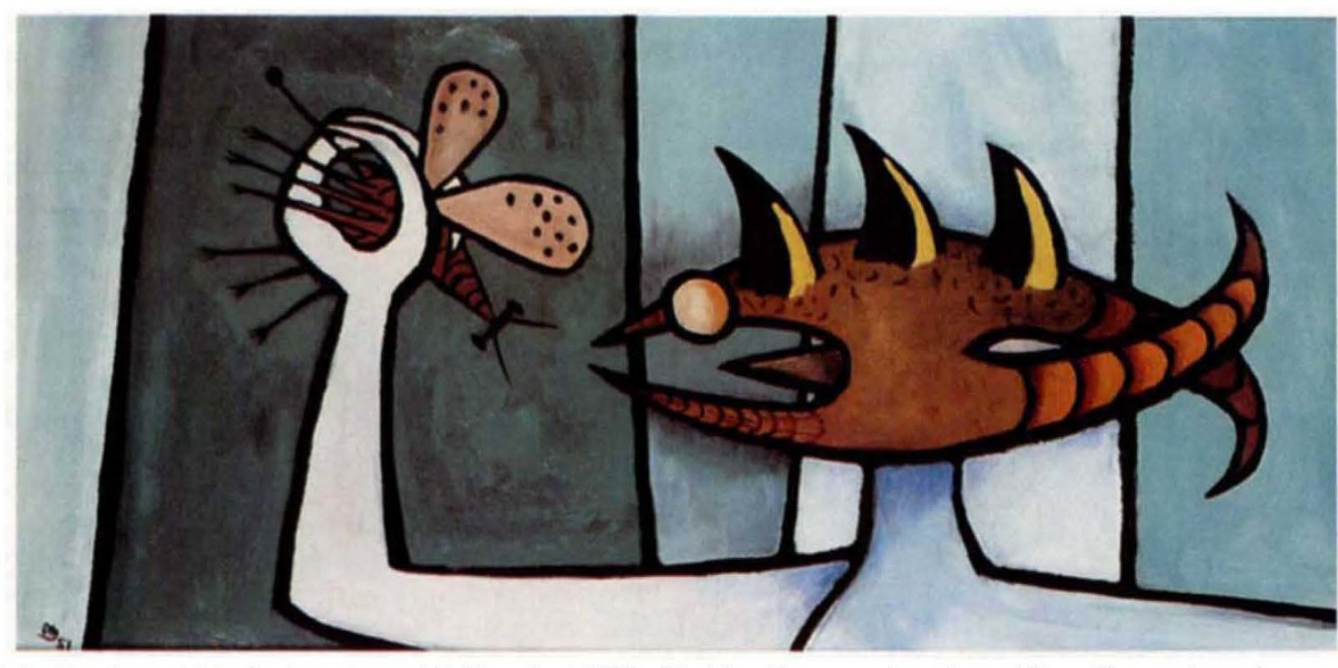
violence and biological activity". He shared his first major exhibition in 1950 with his other mentor, Joan Miro. Shown here is one of a series of 'portraits' from 1951 (now in the collection of Dr John Godfrey), The Zoologist, in which stark lines and aggressive transformations intrude into Morris's comments on social functions. These paintings and many others appear in a retrospective text The Surrealist World of Desmond Morris by Michel Remy (Jonathan Cape, London, 1991; price £35). 